TENDENCIAS

Revista de la Facultad de Ciencias

Económicas y Administrativas.

Universidad de Nariño

ISSN-E 2539-0554

Vol. XXII No. 2 - 2do Semestre 2021

Julio-Diciembre - Páginas 182-212

\title{
IMPACTO DE LAS ACCIONES DE MITIGACIÓN DEL COVID-19 EN LA INFORMALIDAD LABORAL RURAL EN COLOMBIA ${ }^{1}$
}

\author{
IMPACT OF COVID-19 MITIGATION ACTIONS ON RURAL LABOR \\ INFORMALITY IN COLOMBIA
}

\section{IMPACTO DAS ACÇÕES DE MITIGAÇÃO DA COVID-19 NA INFORMALIDADE DO TRABALHO RURAL NA COLÔMBIA}

Héctor Alberto Botello Peñaloza; Isaac Guerrero Rincón

\begin{abstract}
Magíster en Ciencias Económicas, Economía. Universidad Nacional. Investigador Junior Grupos de Investigación en Desarrollo Regional y Ordenamiento Territorial. Universidad Industrial de Santander. ORCiD: 0000-0002-7795-2590. E-mail: hbotellop@unal.edu.co, Colombia.

Magíster en Ciencias Económicas, Economía. Universidad Nacional. Director Grupo de Investigación en Desarrollo Regional y Ordenamiento Territorial. Universidad Industrial de Santander. ORCiD: 0000-0001-5794-2742. E-mail: iguerrin@ uis.edu.co, Colombia.
\end{abstract}

Recibido: 3 de septiembre de 2020

Aprobado: 15 de marzo de 2021

DOI: https://doi.org/10.22267/rtend.212202.173

\section{Resumen}

El coronavirus ha llegado a ser un reto para los gobiernos del mundo tanto en el aspecto de salubridad como económico. Las cuarentenas, el cierre de las empresas, el distanciamiento social y otras políticas amenazan el crecimiento económico y del empleo. El presente documento busca

\footnotetext{
${ }^{1}$ Este artículo es resultado de la investigación aprobada por la Vicerrectoría de Investigación de la Universidad Industrial de Santander denominado "Retos y desafíos de la covid-19: viabilidad de la aplicación de un modelo de ingreso mínimo vital en el departamento de Santander".
} 
analizar la evolución de la informalidad laboral en el sector rural colombiano en el periodo antes y después de la puesta en marcha de las políticas que mitigan el contagio del coronavirus. El periodo analizado utiliza los microdatos de las encuestas de hogares entre enero y mayo de 2019 y 2020 para contrastar la evolución de la tasa de informalidad. Entre los resultados se observó una reducción anual del $20 \%$ en el número total de trabajadores que son informales. Por su parte, la tasa de informalidad se ha mantenido en los mismos niveles antes de la pandemia (mayo 2019). Sin embargo, estos resultados se presentaron por la caída en el número de trabajadores ocupados que hacen parte de la población económicamente activa, los cuales han migrado hacia la población inactiva en labores dentro del hogar.

Palabras clave: desempleo; mercado laboral; Oaxaca Blinder; pandemia; ruralidad. JEL: J01; J31; J21

\begin{abstract}
The coronavirus has become a challenge for governments around the world both in terms of health and economics. Quarantines, business closures, social distancing, and other policies threaten economic and employment growth. This document seeks to analyze the evolution of labor informality in Colombia's rural sector in the period before and after the implementation of policies that mitigate the spread of the coronavirus. The period analyzed uses microdata from household surveys between January and May 2019 and 2020 to contrast the evolution of the informality rate. Among the results, a 20\% annual reduction in the total number of workers who are informal was observed. For its part, the rate of informality has remained at the same levels before the pandemic (May 2019). However, these results were presented by the fall in the number of employed workers who are part of the economically active population, who have migrated to the inactive population for work within the home.
\end{abstract}

Keywords: unemployment; labor market; Oaxaca Blinder; pandemic; rurality. JEL: J01; J31; J21

\title{
Resumo
}


O coronavírus tornou-se um desafio para os governos de todo o mundo, tanto em termos de saúde quanto em termos econômicos. Quarentenas, fechamento de empresas, alienação social e outras políticas ameaçam o crescimento econômico e de emprego. Este documento procura analisar a evolução da informalidade trabalhista no setor rural da Colômbia no período antes e depois da implementação de políticas que mitiguem a propagação do coronavírus. O período analisado utiliza microdados de pesquisas domiciliares entre janeiro e maio de 2019 e 2020 para comparar a evolução da taxa de informalidade. Entre os resultados, foi observada uma redução anual de $20 \%$ no número total de trabalhadores que são informais. A taxa de informalidade permaneceu nos mesmos níveis antes da pandemia (maio de 2019). Entretanto, estes resultados são devidos à queda no número de trabalhadores empregados que fazem parte da população economicamente ativa, que migraram para a população inativa para trabalhar dentro de casa.

Palavras-chave: desemprego; mercado de trabalho; Oaxaca Blinder; pandemia; ruralidade. JEL: J01; J31; J21

\section{Introducción}

La pandemia causada por el coronavirus es una situación de emergencia de salud pública mundial, que se ha convertido en una crisis económica internacional que podría superar cualquier otra crisis económica del reciente milenio. La amplia capacidad contagiosa del virus exigió el uso de complejos modelos epidemiológicos para predecir el curso de la epidemia (Liu et al., 2020). Asimismo, ha impulsado la puesta en marcha de medida de contención y mitigación para limitar la propagación del virus y salvar vidas (Hsiang et al., 2020). Sin embargo, el costo económico asociado ha implicado la reducción significativa de la actividad económica. El impacto podría ser mayor en los países en desarrollo dado que sus sistemas de salud cuentan con menores recursos mercados financieros menos profundos, capacidad fiscal limitada y un manejo institucional más débil.

En contraprestación los gobiernos han puesto en marcha cuantiosos planes de subsidios y transferencias condicionadas que han buscado soportar la demanda agregada en pro de mantener los niveles de producción (Banco Mundial, 2020). En Latinoamérica, el gasto público se ha orientado a los sectores más vulnerables de la población, incluidos los que no pueden trabajar o 
han perdido su empleo como resultado de las medidas de contención. Los recursos se han transferido a los hogares identificados como vulnerables dentro de los programas sociales ya establecidos, así como mayores transferencias directas como el seguro de desempleo y efectivo. Otras políticas fiscales han estado orientadas a la suspensión de ciertos impuestos y las devoluciones de otros.

Según el Banco Mundial las magnitudes de los programas de estímulo fiscal han sido diversos entre países (Banco Mundial, 2020). Brasil, Chile y el Perú tienen estímulos entre el 6\% y 7\% de su PIB, estos son comparables en tamaño a los paquetes adoptados por las economías avanzadas. En el caso de otros países, como Colombia los paquetes han sido cercanos al 1,5\% del PIB ${ }^{2}$.

Según el Banco Mundial, Colombia, junto a Argentina, ha sido uno de los países más restrictivos del mundo al extender su cuarentena condicionada por más de 150 días. El efecto de estas políticas ha sido la reducción de la actividad económica de manera significativa. Según el indicador de seguimiento económico publicado por el Departamento Nacional de Estadística (DANE), la actividad económica se ha reducido en un $16 \%$ hasta mayo. Estas políticas también han tenido un impacto en el empleo, según la misma entidad, la tasa de desocupación se ha elevado en mayo de 2020 hasta el $21 \%$ desde el $10 \%$ reportado en el mismo periodo de 2019. Lo cual puede impactar negativamente los avances evidenciables en reducción pobreza que ha realizado Colombia en los últimos treinta años (García y Castellanos, 2018).

Asimismo, se pueden afectar el mercado laboral informal. Según Mora y Muro (2014), en las décadas de los ochentas y de los noventas del siglo pasado, las tasas de informalidad en Colombia eran del $60 \%$. En 2020, cerca de 10 millones de trabajadores son identificados como informales, lo cual representa a la mitad de la fuerza laboral. La importancia que tiene el sector informal obliga a hacer un estudio tanto de su evolución como de sus determinantes en la época del coronavirus.

\footnotetext{
${ }^{2}$ Sin embargo, el Observatorio Fiscal de la Universidad Javeriana ha resaltado que es difícil conocer la magnitud concreta de los recursos efectivamente destinados dentro de la pandemia. Dado que no hay informes gubernamentales y planes concretos de gastos.
} 
Conocer este aspecto es relevante para la elaboración de la política pública que ayude a mitigar este fenómeno. En este orden de ideas, el objetivo de este trabajo es observar la evolución y determinantes de la informalidad rural en Colombia para el periodo de enero y mayo de 2020. El mercado laboral rural es interés de estudio dado que la constitución del empleo es significativamente diferente y esto es relevante al momento de diseñar instrumentos de política pública para promover la formalización de los trabajadores (Otero, 2019). Colombia es un país con alta informalidad laboral rural. La cobertura pensional rural es inferior al 15\%. Este hecho hace que dichos empleos sean considerados de baja calidad y remuneración. En Colombia, son importante los choques migratorios negativos sobre salarios y empleo del desplazamiento forzoso y el conflicto armado. Adicionalmente, existe una baja participación femenina con altas tasas de desempleo las de los hombres y mujeres urbanas (Otero, 2019)”.

El trabajo se organiza de la siguiente manera. En la segunda sección se presentan las teorías asociadas a la nidificación de las actividades informales. En la tercera, se exponen los trabajos relacionados con el estudio de la informalidad laboral y sus determinantes en Colombia. A continuación, se compilan las políticas económicas puestas en marcha para la mitigación del coronavirus en Colombia. En la quinta parte se presenta el diseño metodológico. Esta se divide en una presentación del modelo aplicado y las fuentes de investigación. Finalmente se presentan los resultados de los ejercicios cuantitativos y las conclusiones.

En este trabajo se incluyeron el nivel educativo, la edad, el sexo, el área donde se localiza el hogar, el tamaño y localización de la empresa y el estado civil.

\section{Enfoques teóricos sobre la informalidad}

La literatura económica ha reconocido a las actividades informales como altamente heterogéneas dado que las relaciones laborales y decisiones de los individuos se determinan por razones diferentes. Existen decisiones empresariales que pueden estar ligadas al sector formal de la economía y otras determinadas por las limitadas opciones laborales para obtener ingresos.

En Latinoamérica, dos enfoques teóricos han conceptualizado la informalidad laboral: el estructuralista e institucionalista. Sin caer en la comparación de estos dos enfoques teóricos para 
decidir cuál es el más apropiado, se intenta buscar la utilidad que puedan ofrecer para entender la evolución de la informalidad laboral. Estos dos enfoques pueden pensarse como explicaciones parciales que pueden llegar a complementarse.

El análisis de corte estructuralista presenta la informalidad laboral como un escaso desarrollo del sector económico, lo que no permite abarcar la fuerza laboral por completo y ese excedente de población, sea mano de obra calificada o no, se ve obligado a laborar de una forma ilegal, recibiendo una baja remuneración o en el peor de los casos en desempleo. Lo que en la literatura actual se conoce como dimensión de exclusión de la informalidad (Perry, 2008). Bajo este enfoque estructuralista relucen varios trabajos de Lewis (1954) o Hart (1970) entre otros.

Por su parte, la teoría institucionalista explica que la existencia de la informalidad se deriva de los altos costos y obstáculos que se imponen a la constitución, funcionamiento, legalización y desempeño de una empresa en un marco de legalidad institucional. Este marco es el establecido por el Estado o las instituciones encargadas de las regulaciones tributarias, sanitarias, laborales, pagos de servicios públicos de actividad económica, ambientales, etc. La capacidad individual de los agentes en tomar decisiones permite que opten por la informalidad antes de enfrentar todos los costos de transacción que requiere la conformación de una empresa legalmente constituida, a esto se le suma la corrupción gubernamental que entorpece aún más el proceso de legalización en el sector formal.

Otro de los factores que impiden la formalización empresarial es el alto costo de financiamiento o la estreches del mercado de crédito. Según la literatura esto es cierto en una cantidad amplia de países en desarrollo (Botello, 2015). Esta situación restringe la capacidad de endeudamiento elevando los tipos de interés que las entidades financieras manejan. Como consecuencia, las unidades económicas con bajo patrimonio o no legalizado, no pueden adquirir deudas para crecer, invertir o emprender. Teniendo en cuenta que los agentes toman las decisiones en base al costobeneficio y sus opciones se segmentan al sector formal o informal. Se puede decir que la teoría institucionalista es el resultado de una decisión voluntaria, donde los altos costos de transacción en el sector formal inciden para que sea más atractivo y beneficioso ingresar al sector informal. 
Sin embargo, hay otras aproximaciones a la informalidad. Para De Soto et al. (1987) el crecimiento de las ciudades en América latina ha impulsado procesos de exclusión social y segregación espacial, cuya consecuencia más notoria es la proliferación del acceso informal e ilegal a la vivienda y al suelo urbanos.

En resumen, la teoría institucionalista se comporta pro cíclicamente y los trabajadores informales son personas con un nivel académico importante, lo que despierta un espíritu emprendedor y quienes eligen la informalidad como opción de bienestar más no por obligación. Lo contrario sucede en el enfoque estructuralista, donde los informales son personas pobres, quienes se encuentran en ese sector por necesidad. En sí mismas, ambas teorías explican la informalidad laboral de diferentes perspectivas, pero su fin es encontrar soluciones ante la pobreza, la necesidad de subsistencia de los individuos para alcanzar un bienestar social óptimo.

\section{Estudios de la informalidad en Colombia}

Para materia de contextualización se hace un breve repaso sobre los estudios realizados de la informalidad en Colombia. Las causas de la informalidad son estructurales a la economía colombiana (Arango y Posada, 2001). Desde 1999, una de cada cinco personas dispuestas a trabajar no encuentran dónde emplearse. Este nivel de desempleo es el más alto que haya conocido el país y también el más elevado de América Latina (García y Cruz, 2017). A partir de esa problemática el fenómeno de la informalidad aumenta de manera exponencial y a su vez despierta el interés de su investigación en el país.

Posteriormente, Ortiz et al. (2007) en base a un marco teórico estructuralista selecciona los años pares del periodo 1988-2000 y utiliza la Encuesta de Hogares para las diez principales áreas metropolitanas. Dentro de un modelo econométrico de data panel, escoge la participación porcentual del sector industrial como variable independiente dentro del PIB departamental para efectos de examinar la evolución del desarrollo industrial de las regiones y su relación con la informalidad laboral urbana. Como resultados se obtienen que distancias con otras áreas urbanas y la estructura productiva, influyen de manera causal sobre el incremento de la informalidad laboral. 
Uribe et al. (2008) encontró en su diagnóstico sobre el mercado laboral: "que una mayor dinámica industrial, mayores esfuerzos del gobierno para evitar la informalidad, mayor presencia institucional y mayor dotación de capital humano de la población ocupada” son ingredientes para combatir el incremento de la informalidad en el mercado laboral colombiano (Uribe et al., 2008, p. 21).

En esta misma línea, Bustamante (2011), con la finalidad de crear políticas públicas para contrarrestar desde el Ministerio de Hacienda la informalidad, hace un análisis sobre los obstáculos que existen en Colombia para entrar en el sector formal, teniendo en cuenta aspectos individuales, institucionales y sectoriales. Identifica las problemáticas que enfrentan en el país los trabajadores informales, entre ellas la falta de educación, poca cobertura de salud y pensión, la baja participación del sector primario y secundario de la economía, y el bajo ingreso. Las barreras Estatales con un análisis institucionalista como lo hace la autora, sumado a las dificultades socioeconómicas influyen en "la dinámica de la creación de trabajo en los diferentes segmentos del mercado laboral y los flujos de trabajadores entre la economía formal e informal" (Bustamante, 2011, p. 19).

En resumen, se encuentra que los trabajos en Colombia se han abordado desde las corrientes estructuralista e institucionalista, pero con diferentes metodologías. Se pueden enumerar que los factores como el menor crecimiento económico, la mayor presión de la oferta laboral, la abundancia de mano de obra poco calificada y la menor absorción de fuerza laboral del sector industrial, han generado que sean las actividades con menores requerimientos de educación y tecnología las que más peso tengan en la economía.

Estos han demostrado que la informalidad en el mercado laboral atrasa el desarrollo económico de Colombia, además de disminuir el bienestar social (Flórez, 2002). Sin embargo, ningún estudio en Colombia ha podido analizar la evolución de la informalidad bajo un contexto de pandemia. Sin embargo, en otros países el mercado laboral se ha visto seriamente impactado por esta problemática. Coibion et al. (2020) han podido analizarlo en Norteamérica y Canadá. 
Han podido evidenciar una caída significativa en el empleo (20 millones) mucho más que los empleos perdidos durante toda la Gran Recesión. Asimismo, una caída en la capacidad de los trabajadores en buscar nuevos empleos. También encuentran que la desigualdad salarial de género se ha mantenido. No obstante, las empresas están adoptando rápidamente acuerdos para las jornadas de trabajo flexibles. Además, una parte importante de la población ha salido para ser parte de la población económicamente inactiva. Bajo esta perspectiva, los padres ahora tienen que quedarse en casa con sus hijos y colaborarles durante el horario escolar y otras labores del hogar.

Sin embargo, la literatura analizada únicamente se realiza sobre mercados laborales que son diametralmente diferentes al colombiano. Por lo tanto, para contribuir a esta literatura en Latinoamérica y Colombia, se muestra a continuación el diseño metodológico con el cual esta investigación quiere explorar el fenómeno de la informalidad bajo el contexto de la pandemia de Covid-19.

\section{Políticas de COVID en Colombia}

Según Cuesta y Pico (2020), Colombia, junto con Argentina, ha sido uno de los países más restrictivos del mundo al extender su cuarentena condicional por más de 150 días. El efecto de estas políticas ha sido la reducción de la actividad económica de manera significativa. Según el indicador de seguimiento económico publicado por el Departamento Administrativo Nacional de Estadística (DANE), la actividad económica se ha reducido en un 16\% a mayo. Estas políticas también han tenido un impacto en el empleo. Según la misma entidad, la tasa de desempleo ha subido en mayo de 2020 al $21 \%$ desde el 10\% reportado en el mismo periodo de 2019. Esto podría impactar negativamente los evidentes avances en la reducción de la pobreza y la desigualdad que ha logrado Colombia en los últimos treinta años (García y Castellanos, 2018).

El gobierno colombiano ha implementado diferentes políticas a través de diferentes decretos. El primero de ellos, el decreto número 457 de marzo de 2020, estableció restricciones a la circulación de personas, especialmente niños y adolescentes, mayores de 70 años, personas con discapacidad y enfermos que requieran asistencia de personal capacitado. También estableció una cuarentena 
obligatoria para diferentes actividades esenciales (medicamentos, financieras, alimentos) en el territorio nacional.

Como consecuencia, la economía colombiana se ha visto seriamente afectada. La Figura 1 muestra la evolución del crecimiento del PIB anualizado por trimestre. En el primer trimestre de 2020, el PIB acumulado creció un 2,9\%; sin embargo, en el segundo trimestre había caído un 1,9\%. Los sectores económicos más importantes de la economía se han visto afectados de forma heterogénea. Por ejemplo, el PIB agrícola se ha mantenido con un crecimiento del 4\% entre 2019 y 2020. En cambio, el PIB industrial y minero han caído casi un $6 \%$ en términos anuales.

\section{Figura 1}

\section{Crecimiento del PIB en Colombia por sectores económicos}

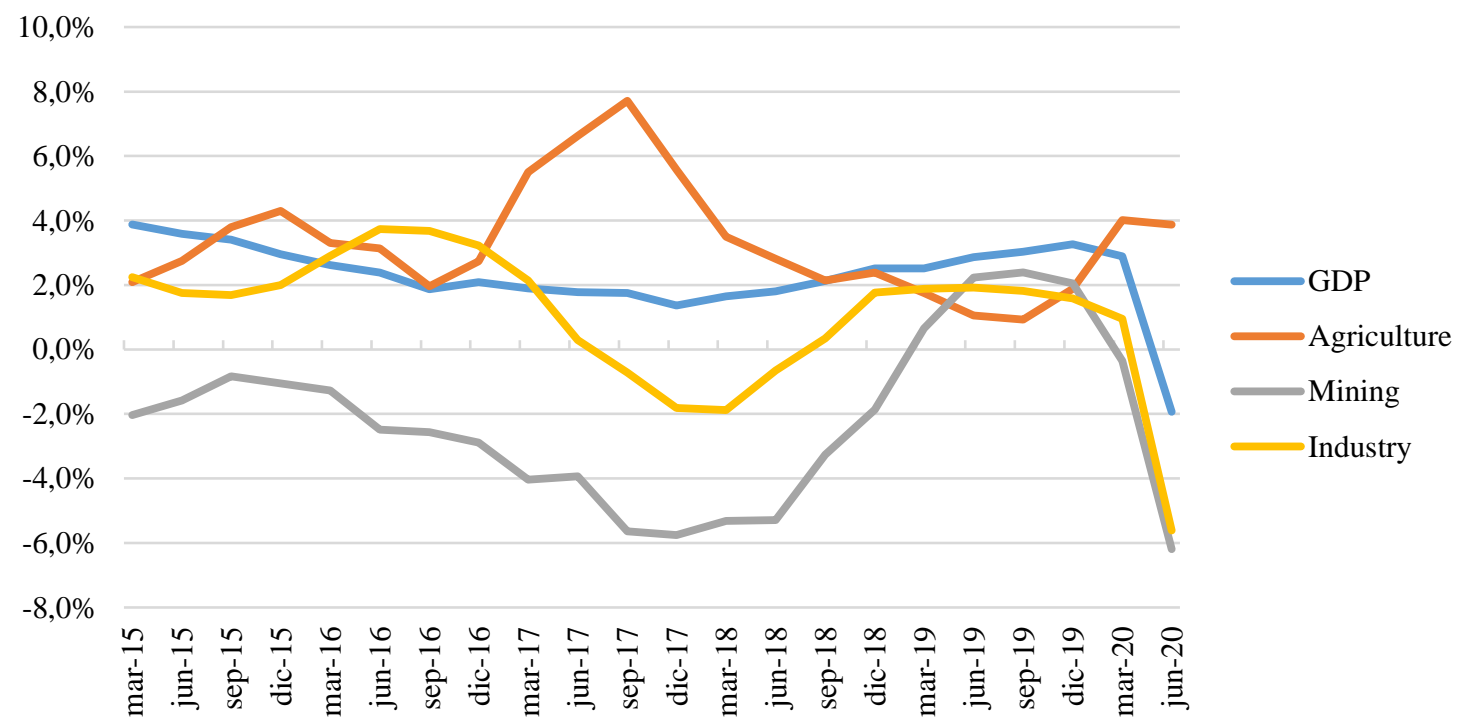

Fuente: Departamento Nacional de Estadística [DANE]. Cuentas Nacionales.

Para responder a estos retos, el gobierno ha implementado diferentes estrategias. A continuación, se presentan los decretos que tuvieron un alcance económico, especialmente los relacionados con el mercado laboral (Tabla 1). 


\section{Tabla 1}

Políticas durante el periodo COVID 19 que afectaron el mercado laboral rural en Colombia

\begin{tabular}{|c|c|}
\hline Política & Fecha \\
\hline Los empresarios podrán dar vacaciones colectivas anticipadas. & $2020-03-17$ \\
\hline $\begin{array}{l}\text { Ingresos extra para las familias que ya reciben ayudas de programas de } \\
\text { transferencia condicionada como "familias en acción", "jóvenes en acción" y } \\
\text { "tercera edad". }\end{array}$ & $2020-03-18$ \\
\hline $\begin{array}{l}\text { El gobierno decreta que el COVID-19 no es una razón aceptable para despedir a } \\
\text { los empleados. }\end{array}$ & $2020-03-19$ \\
\hline $\begin{array}{l}\text { Se aprueba un incentivo económico para el sector rural. Dos pagos de } \$ 80.000 \\
\text { pesos a } 500.000 \text { familias rurales. }\end{array}$ & $2020-03-27$ \\
\hline $\begin{array}{l}\text { El gobierno devuelve un porcentaje del impuesto del IVA a las familias de } \\
\text { menores ingresos. Se espera que esto ocurra } 5 \text { veces en } 2020 .\end{array}$ & 2020-04-01 \\
\hline $\begin{array}{l}\text { Seguro de desempleo para los trabajadores afiliados a un Fondo de } \\
\text { Compensación. Pago de } 2 \text { salarios mínimos en } 90 \text { días. }\end{array}$ & $2020-04-02$ \\
\hline $\begin{array}{l}\text { Nuevo programa de transferencia de efectivo, "renta solidaria", que incluye un } \\
\text { pago único de } 108 \text { dólares para los trabajadores informales y sus familias. Se } \\
\text { trata de } 3 \text { millones de hogares identificados a través de las bases de datos de } \\
\text { recaudación de impuestos y de identificación de hogares vulnerables (SISBEN). } \\
\text { El pago fue programado para la semana del } 30 \text { de marzo al } 5 \text { de abril a través de } \\
\text { la cuenta bancaria para la mitad de los hogares identificados que la tienen; } \\
\text { mediante pagos electrónicos por medio de teléfonos celulares para otros. }\end{array}$ & 2020-04-08 \\
\hline $\begin{array}{l}\text { Los empresarios pueden modificar la carga de trabajo de } 48 \text { horas de la forma } \\
\text { que consideren oportuna (pero sin superar las } 12 \text { horas diarias) para reducir la } \\
\text { sobrecarga de trabajo. }\end{array}$ & $2020-06-03$ \\
\hline $\begin{array}{l}\text { Las empresas con al menos } 3 \text { trabajadores que hayan experimentado una } \\
\text { reducción de ingresos del } 20 \% \text { tienen acceso a una subvención para pagar a sus } \\
\text { trabajadores formales con cargo al PAEF (Fondo de Preservación del Empleo } \\
\text { Formal). }\end{array}$ & 2020-06-04 \\
\hline $\begin{array}{l}\text { El gobierno financia el } 50 \% \text { de los ingresos mensuales adicionales (prima de } \\
\text { trabajo) de los trabajadores con salario mínimo. }\end{array}$ & $2020-06-04$ \\
\hline
\end{tabular}

Fuente: Comisión Económica para América Latina y el Caribe [CEPAL]. Observatorio COVID19 para América Latina y el Caribe.

Cabe destacar que estos conjuntos de normas han buscado suavizar la caída de la demanda agregada, especialmente entre la población más vulnerable, a través de transferencias directas no condicionadas. Los subsidios a la devolución del impuesto al valor agregado (IVA), la renta solidaria y el subsidio a la prima laboral son ejemplos de este tipo de transferencias. El gobierno 
también ha apoyado la oferta agregada reduciendo los costes laborales mediante el pago del salario mínimo.

\section{Metodología}

En una primera aproximación se realiza un análisis descriptivo de los datos de desempleo, informalidad e inactividad de la población en edad para trabajar en Colombia. A continuación, se utiliza un modelo paramétrico con el propósito de conocer las posibles variaciones en los ingresos de la población informal tal y como lo predice el modelo descrito anteriormente.

\section{Medición de la informalidad laboral en Colombia}

La Gran Encuesta Integrada de Hogares (GEIH) es una encuesta realizada por el DANE a partir del 2008. En ésta encuesta el módulo de informalidad se incorpora a todos los meses del año y no sólo al segundo trimestre como en la Encuesta Continua de Hogares. Su medición se realiza y desagrega para las 13 y 23 principales ciudades y sus respectivas áreas metropolitanas.

El Departamento Administrativo Nacional de Estadística (DANE, 2009) atendiendo las recomendaciones de la OIT desarrolla una metodología para el país donde define las ocho ocupaciones laborales que caracteriza a los trabajadores del sector informal en Colombia:

- Empleados particulares y obreros que laboran en establecimientos, negocios o empresas que ocupen hasta cinco personas en todas sus agencias y sucursales, incluyendo al patrono y/o socio.

- Trabajadores familiares sin remuneración.

- Trabajadores sin remuneración en empresas o negocios de otros hogares.

- Empleados domésticos.

- Jornaleros y peones.

- Trabajadores por cuenta propia que laboran en establecimientos de hasta cinco personas, excepto los independientes profesionales.

- Patrones o empleadores en empresas de cinco trabajadores o menos.

- Se excluyen obreros o empleados del gobierno. (DANE, 2009, p. 8) 
Como podemos observar, esta es una visión estrictamente estructuralista. La exclusión social se convierte en un patrón ligado a las características del sector informal, el DANE se enfoca en el estudio las condiciones de los trabajadores, que en su mayoría su perfil se asemeja a su precariedad, bajos salarios o ninguno, poca productividad y educación.

Por este motivo, la Gran Encuesta Integrada Hogares y sus módulos son la principal fuente de información para este trabajo. Esta es una encuesta por muestreo probabilístico que posee cobertura nacional por 23 departamentos. Debido a la emergencia sanitaria por el COVID-19, se redujo el formulario de la Gran Encuesta Integrada de Hogares para los hogares urbanos. Por ejemplo, se excluyó la pregunta de parentesco con el jefe o jefa del hogar. Por lo tanto, no es posible caracterizar a la población ocupada informal para las 23 ciudades y áreas metropolitanas. Sin embargo, esto no ha sido cierto para el área rural. Por eso, utilizar la fuente de información señalada da indicios fieles del comportamiento del mercado laboral informal.

\section{Modelo}

Se aplica el SIR-macro model expuesto en Kermack y McKendrick (1927) y adaptado por Eichenbaum et al. (2020). En este modelo, las probabilidades de transición entre los estados de salud son parámetros exógenos. El modelo asume que la compra de bienes de consumo y el trabajo pone en contacto a las personas entre sí. Estas actividades aumentan la probabilidad de que la infección se extienda. Como resultado, la pandemia tiene efectos tanto de demanda como de oferta laboral. La oferta se contrae debido a que el virus incapacita a las personas que trabajan a la vez que a las personas confinadas por las restricciones impuestas por el gobierno y su riesgo de contagio. La demanda laboral también se contrae dado que las personas al estar confinadas o por el mayor riesgo de contagio disminuyen su consumo y en consecuencias las empresas reducen su producción. Esto es más significativo en sectores como el turismo, los restaurantes y el ocio.

El equilibrio de mercado no se considera óptimo en el sentido paretiano dado que las personas infectadas con el virus no internalizan completamente el efecto en su consumo. Este fallo de mercado no es resultado de la irracionalidad de los agentes o falta de regulación sino por las condiciones de un evento de grandes alcances y no son previstos. Otra de las conclusiones del modelo es que la rigidices nominales de precios hace que las consecuencias a corto plazo en la 
economía sean peores. Por ejemplo, en el mercado laboral, la existencia de un salario mínimo hace que una mayor proporción de trabajadores sean despedidos de sus puestos dado que se impone un piso a las variaciones del precio de equilibrio del salario. A la vez, se espera que mayores trabajadores se trasladen al sector informal para poder conseguir un ingreso que no se puede alcanzar en el mercado formal.

El modelo establece que existe un trade off inevitable entre la disminución de la actividad económica y las consecuencias del virus. Es así como el incremento del desempleo será un resultado observable en el periodo de cuarentena.

Estos resultados han sido estudiados muy recientemente por la literatura de la economía de la salud. Por ejemplo, Alvarez et al. (2020) estudian la política de bloqueo óptimo en una versión del modelo SIR clásico, donde la tasa de mortalidad aumenta con el número de personas infectadas. Estas nuevas implicaciones permiten estudiar los tiempos en los cuales se desarrolla la recesión económica, así como de los impactos de las políticas monetaria y fiscal.

\section{Comparación de ingresos de los ocupados informales}

Es de interés de esta investigación, conocer si se han dado cambios significativos en la distribución salarial dentro del mercado laboral informal. En este sentido, se ha observado un desarrollo significativo de las herramientas estadísticas en el campo de las descomposiciones paramétricas. Esto ha permitido obtener estimaciones más robustas (Goraus y Tyrowicz, 2014).

Los economistas descomponen la brecha salarial en dos partes, una que se explica por las características personales y laborales estándar que se encuentran en los datos de las encuestas (como la edad, la experiencia, el nivel educativo y la industria), y otra que permanece inexplicada (que refleja las diferencias de género en rasgos no observados).

La descomposición de Blinder (1973) emplea los estimadores de la ecuación Minceriana de forma paramétrica. Esta es una metodología que descompone la media de las desviaciones del logaritmo de los salarios de una forma contra-factual. Considerando las diferencias de las poblaciones en dos 
partes: la primera son las características de la dotación de los trabajadores, tales como la educación y la experiencia, y la segunda parte es la residual imputada a las características de control entre los grupos, tales como la nacionalidad, sexo o la raza. Para el caso de esta investigación se quiere explorar si existió un cambio en la distribución salarial entre mayo de 2019 y 2020 . Es decir, lo correspondiente al antes y después del periodo de cuarentena.

La descomposición se organiza de la siguiente manera. En primera instancia, se debe escoger una variable continua como dependiente $(Y)$ y una serie de predictores $(X)$ que pueden ser categóricos o continuos. La ecuación base es la planteada por Mincer y Polachek (1974). Donde la variable dependiente es el salario por hora del trabajador y los componentes independientes son características del trabajador y de la firma. Asimismo, se toman grupos de control. Para esta revisión, el logaritmo de los salarios es la variable a estudiar, el vector de variables independientes, son las relacionadas con el capital humano, la variable de control es la nacionalidad del trabajador. Estas consideraciones se introducen en una ecuación del tipo:

$$
Y_{i}=X_{i}^{\prime} \beta_{i}+u_{i}\left|E\left(u_{i}=0\right)\right| i \epsilon\lfloor A, B\rfloor(1)
$$

Siendo $A$ y $B$ los grupos a controlar. Se encuentra la diferencia dentro del valor esperado de los salarios.

$$
R=E\left(Y_{A}\right)-E\left(Y_{B}\right)
$$

Si se reemplaza 1 en 2 y se asume $E\left(u_{i}=0\right)$, se tiene que:

$$
R=E\left(X_{A}\right)^{\prime} \beta_{A}-E\left(X_{B}\right)^{\prime} \beta_{B}(3)
$$

Para entender todos los efectos que se pueden extraer de la ecuación anterior, se puede realizar la descomposición algebraica expuesta por Daymont y Andrisani (1984)³:

$$
R=\left[E\left(X_{A}\right)-E\left(X_{B}\right)\right]^{\prime} \beta_{A}+\left[E\left(X_{A}\right)^{\prime}\left(\beta_{A}-\beta_{B}\right)\right]+\left[E\left(X_{A}\right)-E\left(X_{B}\right)\right]^{\prime}\left(\beta_{A}-\beta_{B}\right)
$$

\footnotetext{
${ }^{3}$ Para ampliar la explicación matemática, se puede revisar el artículo en el pie de página 6 del documento Daymont y Andrisani (1984).
} 
Estos tres términos conforman los efectos de las interacciones posibles entre los coeficientes, las variables y los valores esperados del ingreso. La ecuación cinco, se puede resumir como una ecuacion que representa una descomposición "three-fold". El primer término se relaciona con las partes de los diferenciales atribuibles a los efectos de la dotación, tales como el capital humano, la experiencia y las características de la firma. El segundo mide las referidas a los coeficientes según los grupos de comparación. En general estos son los considerados como los originados por la característica de control, para esta investigación sería el cambio temporal entre 2019 y 2020 . El último opera sobre las interacciones entre los dos términos antes mencionados.

El procedimiento de la estimacion es por medio de mínimos cuadrados ordinarios, obteniendo por separado los valores esperados de los ingresos laborales. Luego, se calcula el valor esperado si cada uno de los grupos tuviera las características del otro (Botello y López, 2014).

En este punto hay que mencionar que, dentro de la población económicamente activa, la participación laboral ha podido cambiar por causa de la pandemia. Esta evidencia se soporta en los hallazgos encontrados por Llorente (2020) y Coibion et al. (2020). En consecuencia, se debe realizar una corrección a la selección de la muestra. Su enfoque utiliza el procedimiento de corrección de la selección de muestras en dos etapas basado en Heckman (1979). Donde se calcula una ecuación probabilística sobre la participación laboral del individuo con base en sus características socioeconómicas, las cuales motivan esta decisión. En este trabajo se incluyeron el nivel educativo, la edad, el sexo, el área donde se localiza el hogar, el tamaño y localización de la empresa, y el estado civil. El modelo supone la existencia de un conjunto de coeficientes que no son discriminatorios, pero al mismo tiempo son claves para encontrar las diferencias en los predictores. Supóngase que $\beta^{*}$ es un coeficiente hipotético que se puede reemplazar en la ecuación (4) como sigue:

$$
R=\left[E\left(X_{A}\right)-E\left(X_{B}\right)\right]^{\prime} \beta^{*}+\left[E\left(X_{A}\right)^{\prime}\left(\beta_{A}-\beta^{*}\right)\right]+\left[E\left(X_{A}\right)-E\left(X_{B}\right)\right]^{\prime}\left(\beta_{A}-\beta^{*}\right)
$$


A partir de la ecuación (5) se pueden extraer dos efectos, la primera parte es la diferencia explicada por las diferencias en los predictores. El segundo efecto es la unión de los dos últimos términos:

$$
U=\left[E\left(X_{A}\right)^{\prime}\left(\beta_{A}-\beta^{*}\right)\right]+\left[E\left(X_{A}\right)-E\left(X_{B}\right)\right]^{\prime}\left(\beta_{A}-\beta^{*}\right)(6)
$$

Esta se refiere a la parte no explicada por los predictores, la cual se le atribuye, frecuentemente, a la discriminación. No obstante esta también captura el efecto de variables no especificadas dentro del modelo. El procedimiento para esta segunda descomposición es más complejo, dado que el cálculo sobre el beta hipotetico debe realizarse. Una suposición a considerar, es planteada por Oaxaca (1973) quien toma $\beta_{A}=\beta^{*}$ y $\beta_{B}=\beta^{*}$. Es decir que los grupos se intercalan, el grupo A serían étnicos y B sería no étnicos. Otra suposición, que también procede de Oaxaca (1973), existe discriminación de una vía, es decir únicamente las personas que tienen nacionalidad venezolana que se presentan como discriminadas. Sobre la ecuación (6):

$$
R=\left[\overline{X_{A}}-\overline{X_{B}}\right]^{\prime} \hat{\beta}_{A}+X_{B}^{\prime}\left(\hat{\beta}_{A}-\hat{\beta}_{B}\right)(7)
$$

Pero no hay razón para suponer inicialmente que hay discriminación hacia algún grupo en particular. Al configurar $\beta^{*}$ como una suma ponderada, algunas estimaciones que Cotton (1988), postula como ejemplos:

$$
\begin{aligned}
& \beta^{*}=\frac{n_{A}}{n_{A}+n_{B}} \hat{\beta}_{A}+\frac{n_{B}}{n_{A}+n_{B}} \hat{\beta}_{B} \\
& \beta^{*}=0.5 \hat{\beta}_{A}+0.5 \hat{\beta}_{B}
\end{aligned}
$$

Observando las diferentes metodologías, para este trabajo se utilizó las ponderaciones dadas por el tamaño originario de los grupos, mostradas en la ecuación (7).

\section{Resultados}

Durante el periodo detallado se muestra como el desempleo se ha incrementado para todas las áreas rurales y urbanas (Figura 2). El desempleo nacional se ha duplicado hasta el 20\% en junio 
de 2020 frente al mismo periodo del año anterior. Las áreas urbanas sufren del mayor desempleo con el $22 \%$ mientras que las rurales superan el $10 \%$.

\section{Figura 2}

Tasa de desempleo por áreas en Colombia. Trimestre móvil enero 2017- junio 2020

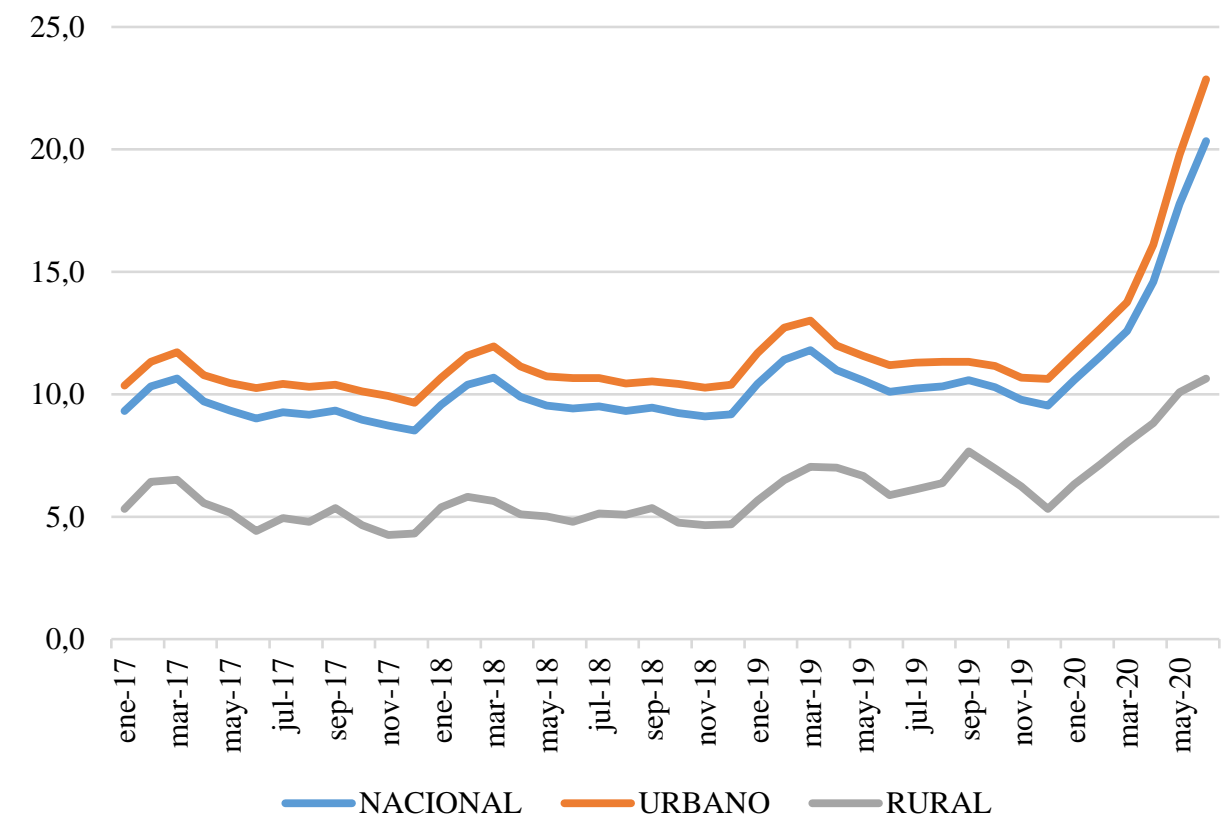

Fuente: cálculos de los autores con base en los datos del DANE.

En relación a la población informal según el criterio del DANE y de la seguridad social, en mayo de 2020 se contabilizaron 3,1 millones de trabajadores bajo esta identificación. Esto representó una caída del $20 \%$ frente un año atrás. En términos relativos, en las Figuras 3 y 4 se detallan la tasa de ocupados en el sector informal en los primeros cinco meses del año 2019 y 2020 . Los dos resultados muestran que cerca del $80 \%$ de los trabajadores de las áreas rurales cubiertas por el DANE son informales. Comparando los datos de ambos años se aprecia una tendencia similar. Siendo decreciente desde el mes de enero hasta mayo. Existe un incremento atípico de la serie en marzo de 2020, el inicio de la cuarentena en Colombia, pero vuelve a la senda desde abril y normal en mayo. 


\section{Figura 3}

Tasa de informalidad criterio DANE

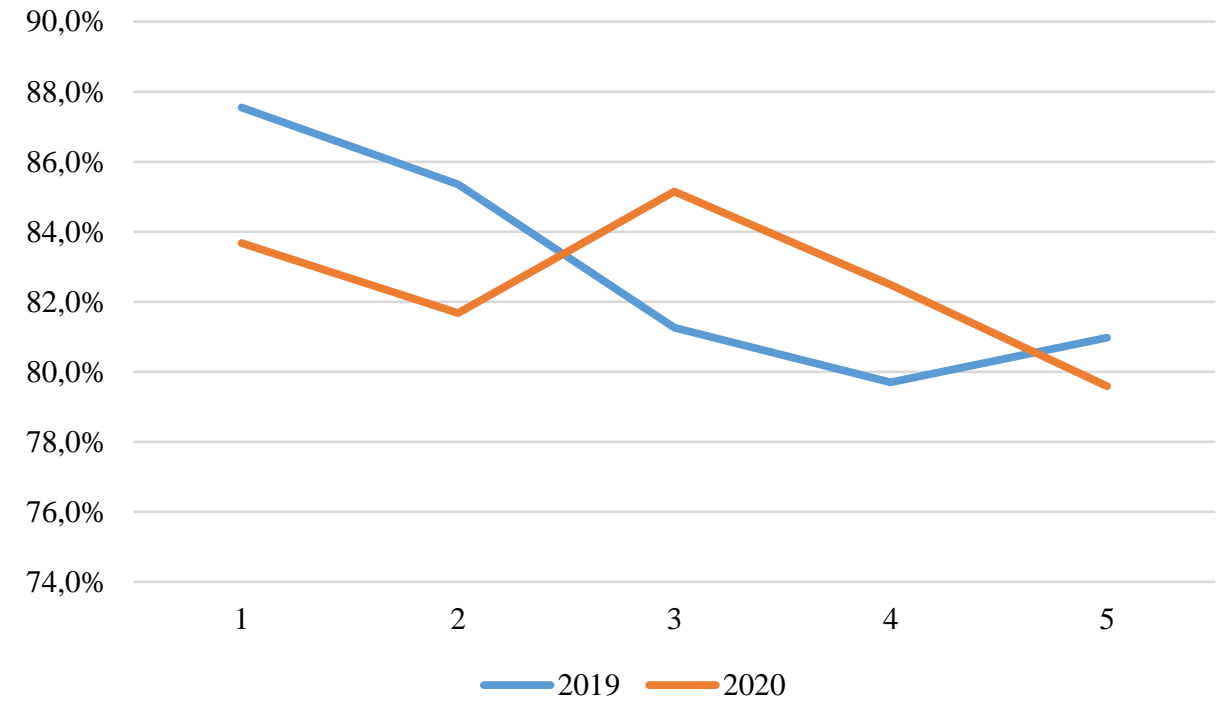

Fuente: cálculos de los autores con base en los datos del DANE.

\section{Figura 4}

Tasa de informalidad criterio de seguridad social

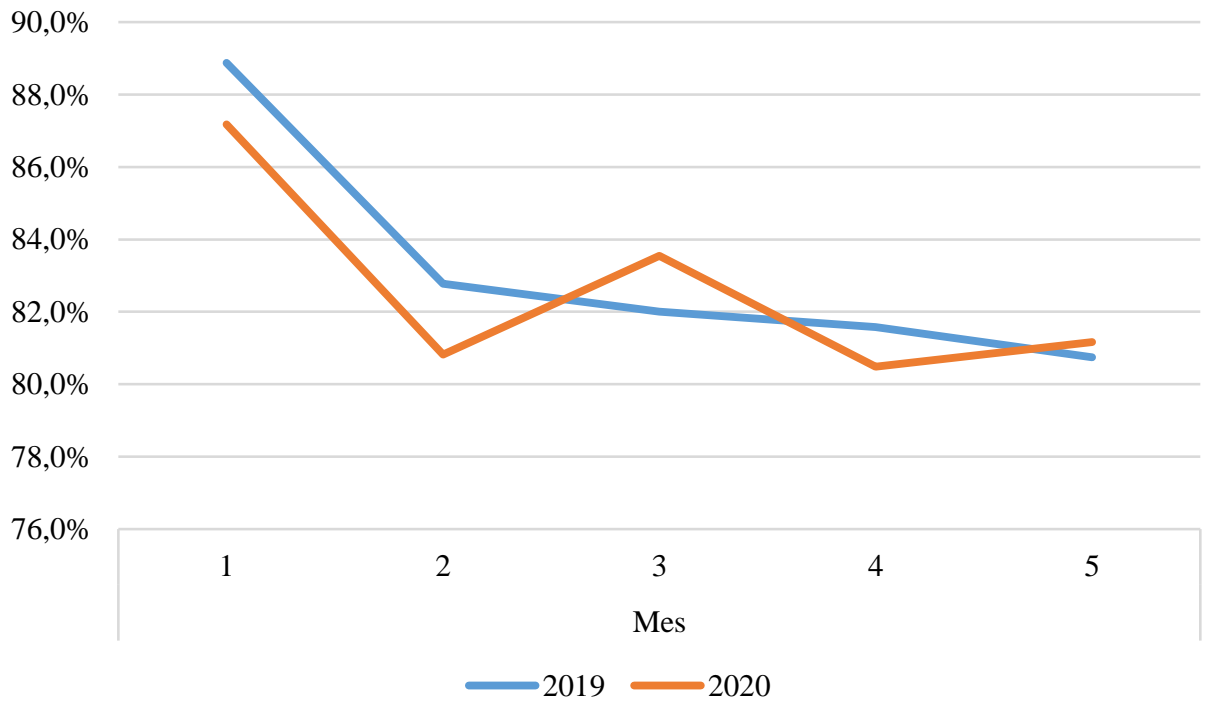

Fuente: Cálculos de los autores con base en los datos del DANE. 
Por sexo, los hombres aumentaron su participación dentro de la población informal, al pasar de componer el 69\% del total en 2019 al 74\% en 2020, la mayor proporción vista desde los últimos 10 años. En el caso de la distribución por departamentos la composición de la población informal se mantuvo de un año a otro.

La Tabla 2 muestra el número de horas laboradas a la semana en el trabajo principal. Todos los tipos de ocupaciones y géneros tuvieron una disminución promedio del $5 \%$ en sus horas trabajadas. Las mujeres fueron las más afectadas tanto en el ámbito formal como informal al disminuir entre 2019 y 2020, 3 horas laborales a la semana.

\section{Tabla 2}

Horas trabajadas a la semana por tipo de ocupación, género y año en las zonas rurales de Colombia. Mayo de cada año

\begin{tabular}{lcrrr}
\hline & \multicolumn{2}{c}{ Formal } & \multicolumn{2}{c}{ Informal } \\
\hline Ocupación & 2019 & 2020 & 2019 & 2020 \\
\hline Empleado privado & 45,09 & 42,76 & 46,84 & 43,29 \\
Gobierno & 35,83 & 34,90 & - & - \\
Cuenta propia & 35,97 & 32,76 & 35,90 & 32,89 \\
Patrón & 44,41 & 44,00 & 44,14 & 39,32 \\
\hline \multicolumn{5}{c}{ Por género } \\
\hline Hombre & 44,88 & 42,26 & 41,62 & 39,04 \\
Mujer & 38,59 & 35,37 & 27,62 & 25,59 \\
\hline
\end{tabular}

Fuente: cálculos de los autores con base en los datos del DANE.

Sin embargo, estos cambios en las tasas de desempleo e informalidad deben estar consideradas por las variaciones en los números de la población económicamente activa e inactiva. Según la Figura 4, entre junio de 2019 y 2020, la población activa disminuyó un 11\% y la población económicamente inactiva aumentó 17\%. La primera se ubicó en 4,5 millones de personas y la segunda subió hasta los 4,3 millones. Esta tendencia es evidenciable desde marzo de 2020. En términos de interpretación, la población total en edad para trabajar ${ }^{4}$ no varió significativamente en conjunto (+1\% o 64 mil personas), eso quiere decir que los cambios observados en la Figura 5

\footnotetext{
${ }^{4}$ En el campo colombiano, para pertenecer a la población en edad para trabajar debe ser mayor de 10 años.
} 
significan que un mayor número de población económicamente activa pasaron a ser parte de la población inactiva debido a la pandemia.

\section{Figura 5}

Evolución de la población en edad para trabajar en las áreas rurales en Colombia

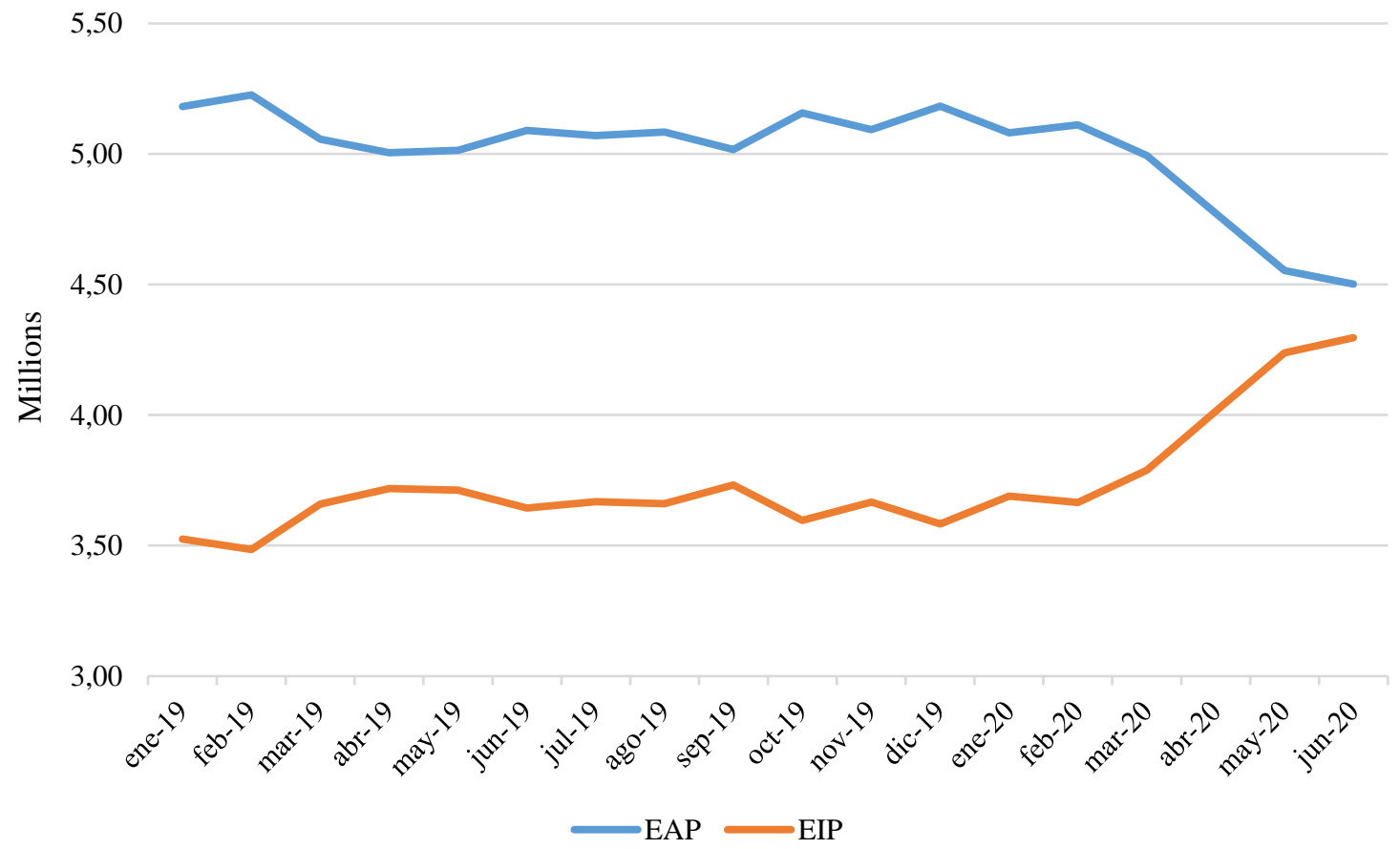

Fuente: cálculos de los autores con base en los datos del DANE.

Según los microdatos de la Encuesta de Hogares del DANE resumidos en la Tabla 3, la mayor proporción de la población activa se reubicó en actividades de oficios del hogar con un incremento de 616 mil personas (25\%) seguido por otras actividades con 333 mil (56\%) y estudiando con 151 mil (10\%). Dentro del concepto de otras actividades, la mitad de los individuos incluyeron que se habían quedado en sus hogares guardando la cuarentena.

\section{Tabla 3}


Actividades de la PET en las áreas rurales en Colombia. Mayo de cada año

\begin{tabular}{lrrrr}
\hline \multicolumn{1}{c}{ Actividad semana pasada } & \multicolumn{1}{c}{2019} & \multicolumn{1}{c}{2020} & Variación \% & \multicolumn{1}{c}{ Var Abs. } \\
\hline Trabajando & 3.847 .566 & 2.839 .589 & $-26 \%$ & -1.007 .977 \\
Buscando trabajo & 138.500 & 122.064 & $-12 \%$ & -16.436 \\
Estudiando & 1.540 .917 & 1.692 .402 & $10 \%$ & 151.485 \\
Oficios del hogar & 2.482 .063 & 3.098 .535 & $25 \%$ & 616.472 \\
Incapacitado permanente & 127.242 & 115.380 & $-9 \%$ & -11.862 \\
Otra actividad & 596.819 & 930.021 & $56 \%$ & 333.202 \\
Total & 8.733 .107 & 8.797 .991 & $1 \%$ & 64.884 \\
\hline
\end{tabular}

Fuente: cálculos de los autores con base en los datos del DANE.

Sin embargo, los cambios en las actividades desarrolladas por los trabajadores durante la pandemia se diferencian de manera significativa por sexo. Los datos discriminados por genero se encuentran en la Tabla 4. Por ejemplo, la población trabajadora femenina se redujo en 347 mil, un 41\%, entre mayo de 2019 y 2020; mientras que la masculina disminuyó 21\% lo equivalente a 660 mil. Las mujeres pasaron a engrosar la categoría de los oficios del hogar. No obstante, dentro de este renglón, la población masculina también se incrementó (177\%) pasando de 175 mil en 2019 a 476 mil en 2020. Finalmente, el resto de la población trabajadora masculina que dejó de trabajar se trasladó al renglón de otras actividades, que sumo 328 mil personas a este rubro.

\section{Tabla 4}

Actividades de la PET en las áreas rurales en Colombia. Mayo de cada año

\begin{tabular}{lrrrrrr}
\hline \multirow{2}{*}{$\begin{array}{c}\text { Actividad semana } \\
\text { pasada }\end{array}$} & \multicolumn{3}{c}{ Hombre } & \multicolumn{3}{c}{ Mujer } \\
\cline { 2 - 6 } & \multicolumn{1}{c}{2019} & \multicolumn{1}{c}{2020} & Variación & \multicolumn{1}{c}{2019} & \multicolumn{1}{c}{2020} & \multicolumn{1}{c}{ Variación } \\
\hline Trabajando & 3.004 .797 & 2.344 .693 & -660.104 & 842.769 & 494.896 & -347.873 \\
Buscando trabajo & 114.342 & 100.439 & -13.903 & 24.158 & 21.625 & -2.533 \\
Estudiando & 857.427 & 937.847 & 80.420 & 683.490 & 754.555 & 71.065 \\
Oficios del hogar & 175.855 & 476.837 & 300.982 & 2.306 .208 & 2.621 .698 & 315.490 \\
Incapacitado & 66.441 & 64.808 & -1.633 & 60.801 & 50.572 & -10.229 \\
Otra actividad & 429.186 & 758.119 & 328.933 & 167.633 & 171.902 & 4.269 \\
Total & 3.004 .797 & 2.344 .693 & 34.695 & 4.087 .078 & 4.117 .268 & 30.189 \\
\hline
\end{tabular}

Fuente: cálculos de los autores con base en los datos del DANE. 
Los resultados a este nivel coinciden con los alcanzados por Coibion et al. (2020) en Norteamérica y Canadá. En resumen, ha habido un incremento significativo del desempleo que se ha visto suavizado por el traslado de la población activa hacia la inactiva especialmente en el área de cuidados del hogar.

\section{Evolución de ingresos}

Mediante un modelo de descomposición paramétrico Oaxaca-Blinder, se encontraron los diferenciales salariales, para conocer el origen de la variación salarial entre mayo de 2019 y de 2020. Tomando en cuenta como variable dependiente el ingreso laboral por hora de los trabajadores informales, la Tabla 5 expone los resultados de la descomposición ${ }^{5}$.

\section{Tabla 5}

Descomposición salarial por año en las áreas rurales en Colombia

\begin{tabular}{lrrrr}
\hline \multicolumn{1}{c}{ Differential } & \multicolumn{1}{c}{ Coef. } & Std. Err. & \multicolumn{1}{c}{$\mathrm{Z}$} & \multicolumn{1}{c}{$\mathrm{P}>|\mathrm{z}|$} \\
\hline Log (Ing_hora)_2019 & 9,244 & 0,000 & 48,00 & 0,000 \\
Log (Ing_hora)_2020 & 9,264 & 0,000 & 46,00 & 0,000 \\
Diferencia & $-0,020$ & 0,000 & $-71,510$ & 0,000 \\
\hline \multicolumn{5}{c}{ Descomposición } \\
\hline Explicado & $-0,020$ & 0,000 & $-153,440$ & 0,000 \\
Inexplicado & 0,000 & 0,000 & 0,500 & 0,614 \\
\hline
\end{tabular}

\begin{tabular}{lr}
\hline Number of obs & 30.578 .318 \\
\hline $\mathrm{F}(48,30578269)$ & 99.999 \\
\hline Prob $>$ F & 0,00 \\
\hline R-squared & 0,21 \\
\hline Adj R-squared & 0,21 \\
\hline Root MSE & 0,68 \\
\hline
\end{tabular}

Nota: Solo se toman datos de mayo de cada año. Controles: Educación, sexo, edad, ocupación, tamaño de la empresa, departamento.

Fuente: cálculos de los autores con base en los datos del DANE.

\footnotetext{
${ }^{5}$ El desarrollo completo de la descomposición se incluye en el Anexo A.
} 
Se aprecia un crecimiento del $2 \%$ en el ingreso laboral por hora de los trabajadores informales entre el 2019 y 2020. Esta diferencia es significativamente estadística al rechazarse al 1\% la hipótesis nula de que el coeficiente relacionado con la variación es igual a cero. La diferencia se explica estadísticamente por las características observables dado que el componente inexplicado no es significativo desde el punto de vista estadístico.

Desde el punto de vista del componente explicado, la Figura 6 expone el aporte de las variables a la parte explicada de la diferencia salarial entre periodos. La base es el año 2020. La mayor parte de la diferencial total explicado $(-2 \%)^{6}$ está compuesto por el género de los individuos analizados y el tamaño de la empresa. Las variaciones en la composición de la primera variable determinaron el $0,75 \%$ del total, mientras que las del tamaño de las empresas aportaron el 1,5\%.

\section{Figura 6}

Aporte de las variables a la parte explicada de la diferencia salarial entre periodos

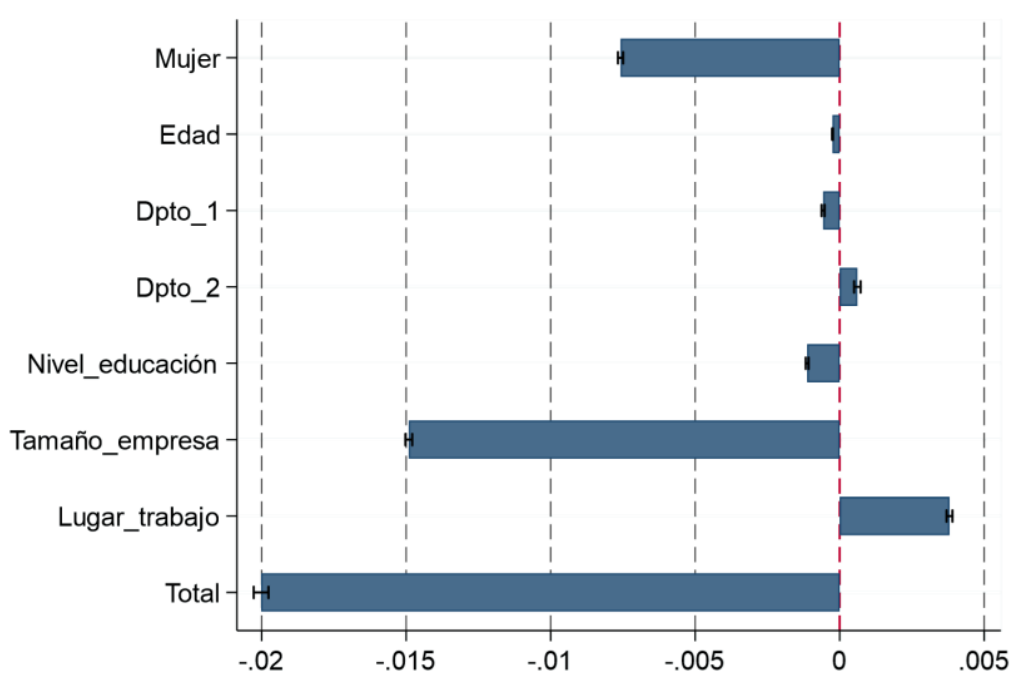

Fuente: cálculos de los autores con base en los datos del DANE.

Para explicar estas variaciones relacionadas con el tamaño de la empresa, se expone el cambio en la distribución de esta variable en el periodo analizado. La Tabla 6 muestra los resultados de este procedimiento.

\footnotetext{
${ }^{6}$ Significa un incremento de 2019 a 2020.
} 


\section{Tabla 6}

Distribución de los trabajadores informales por tamaño de la empresa donde laboran. Áreas rurales en Colombia. Mayo de cada año

\begin{tabular}{lrrrr}
\hline \multirow{2}{*}{ Tamaño } & \multicolumn{2}{c}{ Trabajadores } & \multicolumn{2}{c}{ Participación } \\
\cline { 2 - 5 } & \multicolumn{1}{c}{2019} & \multicolumn{1}{c}{2020} & 2019 & 2020 \\
\hline Trabaja solo & 1.885 .007 & 1.580 .921 & 47,98 & 50,08 \\
2 a 3 personas & 1.355 .936 & 986.317 & 34,51 & 31,24 \\
4 a 5 personas & 542.234 & 404.377 & 13,8 & 12,81 \\
6 o más personas & 145.382 & 185.425 & 3,69 & 5,88 \\
\multicolumn{1}{c}{ Total } & 3.928 .559 & 3.157 .040 & 100 & 100 \\
\hline
\end{tabular}

Fuente: cálculos de los autores con base en los datos del DANE.

Se aprecia que ha habido una destrucción importante de empleo en la parte baja de estructura salarial, la correspondiente a pequeñas empresas. En este sentido, los trabajadores que laboran solos, perdieron cerca de 400 mil puestos de trabajo. Esta misma variación es presentada por las empresas de 2 a 3 personas. Por su parte las mayores empresas (6 o más) incrementaron en 40 mil sus contrataciones. Según Mondragón-Vélez et al. (2011) estos son los trabajadores con mejores salarios por hora dentro del conjunto de los informales. En consecuencia, el cambio en la distribución salarial se puede explicar por las variaciones de los grupos ocupacionales ya mencionados.

\section{Conclusiones}

Esta investigación analizó la evolución y composición de la informalidad laboral en Colombia utilizando los microdatos de la población ocupada, inactiva y desocupada. El periodo cubierto es entre enero y mayo de 2020, comparándolo con el mismo periodo de 2019. Entre los resultados se observó una reducción anual del $20 \%$ en el número total de trabajadores que son informales. Por su parte, la tasa de informalidad se ha mantenido en los mismos niveles antes de la pandemia (mayo 2019). Sin embargo, estos resultados se presentaron por la caída en el número de trabajadores ocupados que hacen parte de la población económicamente activa, los cuales han migrado hacia la población inactiva en labores dentro del hogar. En un contexto donde la población en edad para trabajar se mantuvo estable. En este sentido, se puede inferir que muchos de los que 
perdieron sus trabajos no están buscando activamente encontrar nuevos. Si este fuera el caso, la tasa de desempleo hubiera superado el 30\%. El traslado de la población ocupada hacia la inactiva ha sido significativamente diferente entre hombres y mujeres. Los primeros migraron hacia actividades de descanso mientras que las mujeres pasaron a engrosar los oficios del hogar.

En términos de remuneraciones, el modelo tomado como guía augura que bajo un mercado laboral sin rigideces el salario bajaría para ajustarse a los movimientos de la demanda y oferta laboral. Sin embargo, en el mercado informal se observó un incremento del $2 \%$ nominal ( $0 \%$ real) en los ingresos laborales por hora de la población informal. Los orígenes de este movimiento han sido provocados por los cambios en las dotaciones de los trabajadores al ubicarse en empresas de mayor tamaño.

Entre las recomendaciones de política, los agentes tendrán que sopesar cuidadosamente la eficacia y las consecuencias socioeconómicas de las políticas de contención y mitigación, a la vez que atienden las presiones sobre la salubridad. Igualmente, de realizar las acciones epidemiológicas para limitar la propagación del virus mediante el seguimiento y tamizaje masivo. Colombia ha respondido a una política económica de corto plazo donde se centra en la población más vulnerable en pro de suavizar su shock sobre el consumo y las empresas afectadas.

Sin embargo, para el Banco Mundial (2020), el tamaño del estímulo puede ser menos eficaz por las presiones fiscales ya existentes antes de la pandemia. Esto reduce la magnitud de los multiplicadores fiscales y la posibilidad de impulsar la economía (Ilzetzki et al., 2013; Boussard et al., 2013). Igualmente, la capacidad de estimular la economía está determinada por la eficacia de la transmisión de la política monetaria a la economía real (Ndekwu, 2013). Consideramos que los objetivos que deben mantener los gobiernos son la continuidad de los servicios públicos, ampliación de los sistemas de salud y sostener a la población más vulnerable.

En términos de cooperación internacional, la pandemia es una oportunidad para la coordinación de esfuerzos que promuevan las actividades de contención y mitigación. Por ejemplo, impulsando la innovación y la adquisición de nuevos equipos para los sistemas de salud. También, se ha visto 
que el capital social es parte fundamental contra los choques negativos transitorios de ingresos (Botello, 2013). Todos estos efectos podrían ser objeto de futuras investigaciones.

\section{Referencias}

(1) Alvarez, F. E., Argente, D., \& Lippi, F. (2020). A simple planning problem for covid-19 lockdown. National Bureau of Economic Research, (w26981), 1-33. https://doi.org/10.3386/w26981

(2) Arango, L. E. y Posada, C. E. (2001). El desempleo en Colombia. Borradores de Economía Banco de la República, 176, 1-30.

(3) Banco Mundial. (2020). The Economy in the Time of COVID-19. https://openknowledge.worldbank.org/bitstream/handle/10986/33555/9781464815706.pdf?s equence $=10 \&$ is Allowed $=\mathrm{y}$

(4) Blinder, A. S. (1973). Wage discrimination: reduced form and structural estimates. Journal of Human resources, 8(4), 436-455. https://doi.org/10.2307/144855

(5) Botello, H. A. (2013). Capital social y pobreza en Ecuador, 2010-2012. Ánfora, 20(35), 93115 .

(6) Botello, H. A. (2015). Determinantes del acceso al crédito: Evidencia a nivel de la firma en Bolivia. Perfil De Coyuntura Económica, (25), 111-124. https://doi.org/10.17533/udea.pece.n25a06

(7) Botello, H. A. y López, A. (2014). El efecto de la maternidad sobre los salarios femeninos en Latinoamérica. Semestre Económico, 17(36), 13-37. https://doi.org/10.22395/seec.v17n36a1

(8) Boussard, J., De Castro, F., \& Salto, M. (2013). Fiscal multipliers and public debt dynamics in consolidations. In Public Debt, Global Governance and Economic Dynamism (pp. 167211). Springer, Milano.

(9) Bustamante, J. P. (2011). Los retos de la economía informal en Colombia. Notas fiscales, (9), $1-36$.

(10) Coibion, O., Gorodnichenko, Y., \& Weber, M. (2020). Labor markets during the covid-19 crisis: A preliminary view. National Bureau of Economic Research, (w27017), 1-13.

(11) Comisión Económica para América Latina y el Caribe [CEPAL]. (2020). Base de datos de políticas de COVID 19. 
(12) Cotton, J. (1988). On the decomposition of wage differentials. The review of economics and statistics, 70(2), 236-243. https://doi.org/10.2307/1928307

(13) Cuesta, J., \& Pico, J. (2020). The gendered poverty effects of the COVID-19 pandemic in Colombia. The European Journal of Development Research, 32(5), 1558-1591. https://doi.org/10.1057/s41287-020-00328-2

(14)Daymont, T. N., \& Andrisani, P. J. (1984). Job preferences, college major, and the gender gap in earnings. Journal of Human Resources, 19(3), 408-428. https://doi.org/10.2307/145880

(15)De Soto, H., Ghersi, E., Ghibellini, M., \& Vargas, M. (1987). El otro sendero: la revolución informal. Instituto Libertad Democracia.

(16) Decreto 457 de 2020. (2020, 22 de marzo). Presidente de la República de Colombia. Diario oficial No 51.264 . https://dapre.presidencia.gov.co/normativa/normativa/DECRETO\%20457\%20DEL\%2022\% 20DE\%20MARZO\%20DE\%202020.pdf

(17)Departamento Administrativo Nacional de Estadística [DANE]. (2009). Metodología informalidad gran encuesta integrada de hogares - GEIH. https://www.dane.gov.co/index.php/estadisticas-por-tema/mercado-laboral/empleo-informaly-seguridad-social

(18)Eichenbaum, M. S., Rebelo, S., \& Trabandt, M. (2020). The macroeconomics of epidemics. National Bureau of Economic Research, (w26882), 1-48. http://www.nber.org/papers/w26882

(19) Flórez, C. E. (2002). The function of the urban informal sector in employment: Evidence from Colombia 1984-2000 (No. 003595). Universidad de los Andes-CEDE.

(20) García, L. F. y Cruz, M. (2017). Desempleo en América Latina: ¿flexibilidad laboral o acumulación de capital? Problemas del desarrollo, 48(189), 33-56.

(21) García, T. L. y Castellanos, Y. T. (2018). Tributación y pobreza en Colombia: un análisis desde la evolución del impuesto de renta y el índice de pobreza monetaria. Revista Activos, 16(30), 79-98. https://doi.org/10.15332/25005278.5061

(22) Goraus, K., \& Tyrowicz, J. (2014). Gender wage gap in Poland-Can it be explained by differences in observable characteristics? Ekonomia, 36(1), 125-148.

(23) Hart, K. (1970). Small Scale Entrepreneurs in Ghana and Development Planning. The Journal of Development Studies, 6(4), 104-120. https://doi.org/10.1080/00220387008421338 
(24)Heckman, J. J. (1979). Sample selection bias as a specification error. Econometrica: Journal of the econometric society, 47(1), 153-161. https://doi.org/10.2307/1912352

(25)Hsiang, S., Allen, D., Annan-Phan, S., Bell, K., Bolliger, I., Chong, T., Druckenmiller, H., Yue Huang, L., Hultgren, A., Krasovich, E., Lau, P., Lee, J., Rolf, E., Tseng, J., \& Wu, T. (2020). The effect of large-scale anti-contagion policies on the COVID-19 pandemic. Nature, 584, 262-267. https://doi.org/10.1038/s41586-020-2404-8

(26) Ilzetzki, E., Mendoza, E. G., \& Végh, C. A. (2013). How big (small?) are fiscal multipliers? Journal of monetary economics, 60(2), 239-254. https://doi.org/10.1016/j.jmoneco.2012.10.011

(27)Kermack, W. O., \& McKendrick, A. G. (1927). A contribution to the mathematical theory of epidemics. Proceedings of the royal society of London,115(772), 700-721. https://doi.org/10.1098/rspa.1927.0118

(28)Lewis, A. (1954). Economic development with unlimited supplies of labour. The Manchester School, 22, 139-191. https://doi.org/10.1111/j.1467-9957.1954.tb00021.x

(29) Liu, Z., Magal, P., Seydi, O., \& Webb, G. (2020). A COVID-19 epidemic model with latency period. Infectious Disease Modelling, 5, 323-337. https://doi.org/10.1016/j.idm.2020.03.003

(30)Llorente, R. (2020). Impacto del COVID-19 en el mercado de trabajo: un análisis de los colectivos vulnerables. Documentos de Trabajo (IAES, Instituto Universitario de Análisis Económico y Social), (2), 1-29. http://hdl.handle.net/10486/691084

(31) Mincer, J., \& Polachek, S. (1974). Family investments in human capital: Earnings of women. Journal of political Economy, 82(2), S76-S108. http://www.jstor.org/stable/1829993

(32) Mondragón-Vélez, C., Peña, X. y Wills, D. (2011). Rigideces laborales y salarios en los sectores formal e informal en Colombia. Universidad de los Andes-CEDE. http://hdl.handle.net/1992/41014

(33) Mora, J. J., \& Muro, J. (2014). Informality and minimum wages by cohort in Colombia. Cuadernos de Economía, 33(63), 469-486. https://doi.org/10.15446/cuad.econ.v33n63.45342

(34) Ndekwu, E. C. (2013). An analysis of the monetary policy transmission mechanism and the real economy in Nigeria. Central Bank of Nigeria, Research Department. https://www.cbn.gov.ng/out/2014/rsd/occasional\%20paper\%2043.pdf

(35) Oaxaca, R. (1973). Male-female wage differentials in urban labor markets. International economic review, 14(3), 693-709. https://doi.org/10.2307/2525981 
(36) Ortiz, C. H., Uribe, J. I. y García, G. A. (2007). Informalidad y subempleo: un modelo probit bivariado aplicado al Valle del Cauca. Revista Sociedad y economía, (13), 104-131.

(37) Otero-Cortés, A. (2019). El mercado laboral rural en Colombia, 2010-2019. Documento de Trabajo sobre Economía Regional y Urbana, (281), 1-30.

(38) Perry, G. E. (2008). Informalidad: escape y exclusión. Banco Mundial con Mayol Ediciones.

(39) Uribe, J., Ortiz, C. y García, G. (2008). Informalidad y subempleo en Colombia: dos caras de la misma moneda. Cuadernos de Administración, 21(37), 211-241.

Cómo citar este artículo: Botello, H. y Guerrero, I. (2021). Impacto de las acciones de mitigación del COVID-19 en la informalidad laboral rural en Colombia. Tendencias, 22(2), 182-212. https://doi.org/10.22267/rtend.212202.173 


\section{Anexo A}

Resultados del modelo de descomposición de Oaxaca Blinder

\begin{tabular}{|c|c|c|c|c|c|c|}
\hline Variable & Característica & Coeficiente & $\begin{array}{c}\text { Error } \\
\text { estándar }\end{array}$ & $\mathbf{T}$ & $\mathbf{P}>|\mathbf{t}|$ & Base \\
\hline Sexo & Mujer & $-0,2859203$ & 0,000352 & $-812,23$ & 0 & Hombre \\
\hline Edad & & 0,0012214 & 8,98E-06 & 136,07 & 0 & Continua \\
\hline \multirow{5}{*}{$\begin{array}{l}\text { Nivel } \\
\text { educativo }\end{array}$} & $\begin{array}{l}\text { Básica primaria (1o - } \\
\text { 5o) }\end{array}$ & 0,1287637 & 0,0004135 & 311,38 & 0 & \multirow{5}{*}{ Ninguno } \\
\hline & $\begin{array}{l}\text { Básica secundaria } \\
(6 o-9 o)\end{array}$ & 0,1486557 & 0,0005053 & 294,21 & 0 & \\
\hline & Media (10o - 13o) & 0,1989032 & 0,0005008 & 397,18 & 0 & \\
\hline & $\begin{array}{l}\text { Superior o } \\
\text { universitaria } \\
\end{array}$ & 0,5133845 & 0,0011625 & 441,61 & 0 & \\
\hline & No sabe, no informa & 0,3225042 & 0,0070553 & 45,71 & 0 & \\
\hline \multirow{8}{*}{$\begin{array}{l}\text { Tamaño } \\
\text { empresa }\end{array}$} & 2 a 3 personas & 0,2228563 & 0,0003069 & 726,14 & 0 & \multirow{8}{*}{$\begin{array}{l}\text { Cuenta } \\
\text { propia }\end{array}$} \\
\hline & 4 a 5 & 0,4162144 & 0,0004395 & 946,95 & 0 & \\
\hline & 6 a 10 & 0,4239748 & 0,0007782 & 544,8 & 0 & \\
\hline & 11 a 19 & 0,4578314 & 0,0013408 & 341,47 & 0 & \\
\hline & 20 a 30 & 0,5214107 & 0,0017403 & 299,62 & 0 & \\
\hline & 31 a 50 & 0,5141381 & 0,0022307 & 230,48 & 0 & \\
\hline & 51 a 100 & 0,4771744 & 0,0024196 & 197,21 & 0 & \\
\hline & 101 o más & 0,5193926 & 0,0018328 & 283,39 & 0 & \\
\hline \multirow{7}{*}{$\begin{array}{l}\text { Donde } \\
\text { realiza su } \\
\text { actividad } \\
\text { económica }\end{array}$} & En otras viviendas & 0,5682662 & 0,0006261 & 907,66 & 0 & \multirow{7}{*}{$\begin{array}{l}\text { En esta } \\
\text { vivienda }\end{array}$} \\
\hline & En kiosco - caseta & $-0,0441397$ & 0,0023189 & $-19,03$ & 0 & \\
\hline & En un vehículo & 0,5034999 & 0,0007885 & 638,58 & 0 & \\
\hline & De puerta en puerta & 0,414703 & 0,0011683 & 354,96 & 0 & \\
\hline & Sitio al descubierto & 0,3296684 & 0,0009049 & 364,3 & 0 & \\
\hline & $\begin{array}{l}\text { Local fijo, oficina, } \\
\text { fabrica, etc. }\end{array}$ & 0,4312554 & 0,000632 & 682,42 & 0 & \\
\hline & $\begin{array}{l}\text { En una obra en } \\
\text { construcción }\end{array}$ & 0,4867938 & 0,0010932 & 445,29 & 0 & \\
\hline Año & 2020 & $-0,0001252$ & 0,0002484 & $-0,5$ & 0,614 & 2019 \\
\hline Constante & & 9,282441 & 0,5015471 & 18,51 & 0 & \\
\hline
\end{tabular}

Fuente: cálculos de los autores con base en los datos del DANE. 